Full Length Article

\title{
Potassium and soot interaction in fast biomass pyrolysis at high temperatures
}

\author{
Anna Trubetskaya ${ }^{\mathrm{a}, *}$, Flemming Hofmann Larsen $^{\mathrm{b}}$, Andrey Shchukarev ${ }^{\mathrm{c}}$, Kenny Ståhl ${ }^{\mathrm{d}}$, \\ Kentaro Umeki ${ }^{\mathrm{e}}$ \\ a Thermochemical Energy Conversion Laboratory, Umeå University, 90187 Umeå, Sweden \\ ${ }^{\mathrm{b}}$ Department of Food Science, University of Copenhagen, Rolighedsvej 26, 1958 Copenhagen, Denmark \\ c Department of Chemistry, Umeå University, 90187 Umeå, Sweden \\ d Department of Chemistry, Technical University of Denmark, Kemitorvet B206, 2800 Kongens Lyngby, Denmark \\ energy Science Division, Luleå University of Technology, 97187 Luleå, Sweden
}

A R T I C L E I N F O

\section{Keyword:}

Soot

Potassium

Biomass

Fast pyrolysis

$\mathrm{CO}_{2}$ reactivity

\begin{abstract}
A B S T R A C T
This study aims to investigate the interaction between potassium and carbonaceous matrix of soot produced from wood and herbaceous biomass pyrolysis at high heating rates at $1250^{\circ} \mathrm{C}$ in a drop tube reactor. The influence of soot carbon chemistry and potassium content in the original biomass on the $\mathrm{CO}_{2}$ reactivity was studied by thermogravimetric analysis. The XPS results showed that potassium incorporation with oxygen-containing surface groups in the soot matrix did not occur during high temperature pyrolysis. The potassium was mostly found as water-soluble salts such as $\mathrm{KCl}, \mathrm{KOH}, \mathrm{KHCO}_{3}$ and $\mathrm{K}_{2} \mathrm{CO}_{3}$ in herbaceous biomass soot. The low ashcontaining pinewood soot was less reactive than the potassium rich herbaceous biomass soot, indicating a dominating role of potassium on the soot reactivity. However, the catalytic effect of potassium on the reactivity remained the same after a certain potassium amount was incorporated in the soot matrix during pyrolysis. Raman spectroscopy results showed that the carbon chemistry of biomass soot also affected the $\mathrm{CO}_{2}$ reactivity. The less reactive pinewood soot was more graphitic than herbaceous biomass soot samples with the disordered carbon structure.
\end{abstract}

\section{Introduction}

Entrained flow gasification (EFG) is a promising technology, which generates high quality syngas and small amounts of tars due to the high operating temperatures. However, the high soot yields lead to intensive gas cleaning and can cause a possible plant shut down. The reduction of soot formation increases the overall production system efficiency and improves the economic feasibility and reliability of the gasification plant. Moreover, the alkali metals released from high ash-containing lignocellulosic materials may form molten ash material, and thus, lead to deposition of slag upon the reactor wall $[1,2]$. Continuous extraction of the ash slag from the reactor is required to prevent outlet blockages and to ensure steady syngas production.

The released alkali metal ions in the biomass pyrolysis participate in soot formation and conversion reactions. It is known that alkali metal ions enhance $\mathrm{CO}_{2}$ reactivity of graphite and carbon black [3] and suppress soot formation [4]. The alkali metal ions can form a fly ash or be bonded to oxygen-containing surface groups in the soot matrix $[5,6]$. The fly ash particles contain $\mathrm{K}_{2} \mathrm{~S}, \mathrm{KOH}$ and $\mathrm{K}_{2} \mathrm{CO}_{3}$ [6]. The interaction of $\mathrm{K}_{2} \mathrm{CO}_{3}$ with the low ash-containing coal was investigated under $\mathrm{CO}_{2}$ gasification condition in a thermogravimetric analyzer by Kopyscinski et al. [7]. The pyrolysis results showed that $\mathrm{CO}$ was released from $\mathrm{K}_{2} \mathrm{CO}_{3}$, which was bound to a carbon surface. In the next step, the oxygen from the carbonate reacts further with the surface carbon and forms $\mathrm{CO}$ which leaves the reduced potassium complex of an unknown stoichiometry. In the last step, the transfer of the potassium cluster occurs. During fast pyrolysis, the elemental potassium is unlikely to be released in gas phase at low temperatures. However, little is known about the interaction between the carbonaceous matrix of soot and alkali. In catalytic gasification, the concentration of intercalated species is small, and it decreases with increasing temperature [8,9]. The elemental potassium, bonded to the soot matrix in phenolate groups remained inaccessible for the gaseous reactants, leading to the low catalytic activity [10]. The potassium-carbon complexes form series of stable and metastable phases with different physicochemical properties [11-14]. The $\mathrm{K}-\mathrm{C}_{60}$ complex was investigated using ${ }^{13} \mathrm{C}$ and ${ }^{39} \mathrm{~K}$ solid state NMR [15]. According to the ${ }^{13} \mathrm{C}$ NMR spectra of intercalated graphite $\left(\mathrm{K}_{1} \mathrm{C}_{60}\right)$ it exists as a single phase characterized by a resonance

\footnotetext{
* Corresponding author.

E-mail address: anna.trubetskaya@umu.se (A. Trubetskaya).
} 
at $174 \mathrm{ppm}$ at temperatures above $420 \mathrm{~K}$ [13]. At lower temperatures, two resonances of intercalated graphite at $187 \mathrm{ppm}\left(\mathrm{K}_{3} \mathrm{C}_{60}\right)$ and $143 \mathrm{ppm}\left(\mathrm{K}_{\delta} \mathrm{C}_{60}, \delta \leqslant 1\right)$ were identified by ${ }^{13} \mathrm{C}$ NMR [13]. X-ray photoelectron spectrum of potassium doped double-walled carbon nanotubes showed two peak components at the binding energy of 293.3 and $296 \mathrm{eV}$ (K $2 \mathrm{p}_{3 / 2}$ and $\mathrm{K} 2 \mathrm{p}_{1 / 2}$ of the K-oxides and K-cations) [16]. The Xray photoelectron bands at 294.6 and $293.4 \mathrm{eV}$ were assigned to ionic potassium intercalated within the graphite layers and to oxidized potassium at the surface of graphite [17]. The modeling using density functional theory method (DFT) confirmed the existence of an electron transfer from soot to gaseous oxygen through the active $\mathrm{K}^{+}$sites [18]. In this DFT model, soot structure was represented by graphene layers and potassium was modeled perpendicular to the plane of the soot model and near the zigzag and armchair edges of the soot. The DFT model for the $\mathrm{C}-\mathrm{C}$ armchair face showed that the potassium intercalation in phenolate groups (C-O-K) inhibits the gasification reaction, confirming previous experimental observations $[3,19]$.

This work aims to investigate the interaction between potassium and carbonaceous soot matrix in detail. The specific objectives of this study were to: (1) investigate the interaction of potassium with the carbonaceous matrix of soot produced at high temperatures $\left(1250^{\circ} \mathrm{C}\right)$ in a drop tube reactor, and (2) understand the formation mechanism of potassium-carbon complexes in fast pyrolysis and their effect on the soot reactivity using Raman spectroscopy, X-ray photoelectron spectroscopy (XPS), ${ }^{13} \mathrm{C}$ solid state NMR, X-ray diffraction (XRD), and thermogravimetric analysis (TGA).

\section{Materials and methods}

\subsection{Raw biomass characterization}

Pinewood, beechwood, wheat straw and alfalfa straw were chosen for the fast pyrolysis study in a drop tube reactor (DTF). Fuel selection was based on the differences in the ash composition and plant cell compounds (cellulose, hemicellulose, lignin, extractives), as shown in the supplemental material (Table S-1). The ultimate and proximate analysis of pinewood, beechwood, wheat straw, leached wheat straw and alfalfa straw is shown in Table 1.

\subsection{Pyrolysis with drop tube furnace}

Soot and char samples were obtained from pyrolysis experiments in a drop tube reactor (DTF). Soot samples were generated at $1250^{\circ} \mathrm{C}$ to obtain a maximal soot yield. The DTF setup and operating conditions were described in detail by Trubetskaya et al. [20]. The reactor consists of an alumina tube (internal diameter: $54 \mathrm{~mm}$, tube length: $1.06 \mathrm{~m}$ ) heated by four heating elements with independent temperature control. Gas flow rate into the reactor is regulated by mass flow controllers (ELFLOW $^{\oplus}$ Select, Bronkhorst High-Tech B.V.). The experiments were conducted by feeding $\approx 5 \mathrm{~g}$ of biomass at a rate of $0.2 \mathrm{~g} \mathrm{~min}^{-1}$. Both primary $\left(0.181 \mathrm{~min}^{-1}\right.$ measured at $20^{\circ} \mathrm{C}$ and $\left.101.3 \mathrm{kPa}\right)$ and secondary $\left(4.81 \mathrm{~min}^{-1}\right.$ measured at $20^{\circ} \mathrm{C}$ and $101.3 \mathrm{kPa}$ ) feed gases were $\mathrm{N}_{2}$. The residence time of fuel particles was estimated to be about $1 \mathrm{~s}$, taking into account density changes during pyrolysis. Soot particles passing the cyclone (cut size $2.5 \mu \mathrm{m}$ ) were captured from the product gas flow by a grade QM-A quartz filter with a diameter of $50 \mathrm{~mm}$ (Whatman, GE Healthcare Life Science).

\subsection{Solid residue characterization}

\subsubsection{Ash compositional analysis}

The ash compositional analysis was performed by ICP-OES (DIN EN 15290). Prior to the analysis, soot samples were pre-heated in oxygen at $10^{\circ} \mathrm{C} \min ^{-1}$ up to $550^{\circ} \mathrm{C}$ and kept at that temperature for $7 \mathrm{~h}$.
Table 1

Proximate and ultimate analysis.

\begin{tabular}{|c|c|c|c|c|c|}
\hline Fuel & Pinewood & Beechwood & $\begin{array}{l}\text { Wheat } \\
\text { straw }\end{array}$ & $\begin{array}{l}\text { Alfalfa } \\
\text { straw }\end{array}$ & $\begin{array}{l}\text { Leached } \\
\text { wheat straw }\end{array}$ \\
\hline \multicolumn{6}{|c|}{ Proximate analysis } \\
\hline $\begin{array}{r}\text { Moisture, (wt\% } \\
\text { as received) }\end{array}$ & 5.1 & 4.5 & 5.5 & 5.2 & 4.3 \\
\hline $\begin{array}{c}\text { Ash }\left(550^{\circ} \mathrm{C}\right),(\mathrm{wt} \\
\% \text { dry basis })\end{array}$ & 0.3 & 1.4 & 4.1 & 7.4 & 2.1 \\
\hline $\begin{array}{c}\text { Volatiles, (wt } \% \\
\text { dry basis) }\end{array}$ & 86.6 & 79.4 & 77.5 & 75.9 & 82.2 \\
\hline $\mathrm{HHV},\left(\mathrm{MJ} \mathrm{kg}^{-1}\right)$ & 21.6 & 20.2 & 18.8 & 19.7 & 19 \\
\hline $\mathrm{LHV},\left(\mathrm{MJ} \mathrm{kg}^{-1}\right)$ & 20.2 & 19 & 17.5 & 16.9 & 17.2 \\
\hline \multicolumn{6}{|c|}{ Ultimate analysis, (wt\%, dry basis) } \\
\hline $\mathrm{C}$ & 53.1 & 50.7 & 46.6 & 42.5 & 46.2 \\
\hline $\mathrm{H}$ & 6.5 & 5.9 & 6.1 & 6.7 & 6.8 \\
\hline $\mathrm{O}$ & 40 & 41.9 & 42.5 & 43.1 & 44.9 \\
\hline $\mathrm{N}$ & 0.06 & 0.13 & 0.6 & 0.3 & 0.05 \\
\hline$S$ & $<0.01$ & 0.01 & 0.1 & 0.03 & 0.02 \\
\hline \multicolumn{6}{|c|}{ Ash compositional analysis, (mg $\mathrm{kg}^{-1}$, dry basis) } \\
\hline $\mathrm{Cl}$ & 0.01 & 0.02 & 0.1 & 0.5 & 0.01 \\
\hline $\mathrm{Al}$ & 10 & 10 & 150 & 600 & 100 \\
\hline $\mathrm{Ca}$ & 600 & 2000 & 2500 & 12,900 & 1300 \\
\hline $\mathrm{Fe}$ & 20 & 10 & 200 & - & 350 \\
\hline $\mathrm{K}$ & 200 & 3600 & 11,000 & 28,000 & 1200 \\
\hline $\mathrm{Mg}$ & 100 & 600 & 750 & 1400 & 350 \\
\hline $\mathrm{Na}$ & 30 & 100 & 150 & 1000 & 50 \\
\hline $\mathrm{P}$ & 6 & 150 & 550 & 1900 & 80 \\
\hline $\mathrm{Si}$ & 50 & 200 & 8500 & 2000 & 6200 \\
\hline $\mathrm{Ti}$ & 2 & $<8$ & 10 & 30 & 10 \\
\hline
\end{tabular}

\subsubsection{Potasium ion selective electrode}

The potassium ion-selective membrane electrode Orion 93-19 (Thermo Scientific, USA) was used to determine the amount of leached potassium in deionized water. The electrode potential was measured at room temperature using the Benchtop Meter Orion 720A (Thermo Scientific, USA). Five-points calibration was conducted using potassium chloride solutions with ionic strengths of $10^{-5}, 10^{-4}, 10^{-3}, 0.01$ and $0.1 \mathrm{M}$.

\subsection{3. $X$-ray diffraction}

The XRD analysis of the soot matter was conducted using a Bruker D8 AXS X-ray diffractometer with (Cu-K $\alpha 1, \lambda=1.54056 \AA$ and $\mathrm{Cu}-\mathrm{K} \alpha 2$ radiation, $\lambda=1.54439 \AA$ ) operating in Bragg-Brentano (reflection) mode, using a secondary graphite monochromator, and a scintillation detector, in the range 5 to 80 degrees for $12.5 \mathrm{~h}$. Soot samples were placed in small cups which were rotated during the XRD analysis. The multiple fitting of XRD pattern, crystallite size analysis and peak searches were done using PowderPlot software and Crystallographica Search-Match software (Version 3,1,0,0). The instrumental reflection broadening was subtracted from the experimental pattern by the PowderPlot software.

\subsubsection{Raman spectroscopy}

Raman spectroscopy was performed using an inVia Raman microscope (Renishaw, UK) operating with a $514 \mathrm{~nm}$ laser line at a power of $30 \mathrm{~mW}$. The measurements were performed in static mode with a centre at $1600 \mathrm{~cm}^{-1}$ resulting in a $960-2200 \mathrm{~cm}^{-1}$ spectral region. The laser power was set to $100 \%$ in the software and roughly $30 \%$ in the hardware. $1 \mathrm{~s}$ exposure time was used in normal confocality mode. A 20x lens and $8-15 \mu \mathrm{m}$ step size ( $\mathrm{X}$ and $\mathrm{Y}$ directions) were used for mapping, to generate 100-200 spectra/image for each soot sample. Deconvolution of the Raman spectra were conducted using the peak fit pro tool in the OriginPro software (OriginLab, USA) by combination of five Gaussian-shaped bands (D4, D3, D2, D1, and G) following Sadezky et al. [21] and as described in the supplemental material (Section S10.1). The mean crystal size in the $a$-direction $\left(\mathrm{L}_{a}\right)$ with the fitting constants $\mathrm{C}_{0}=-12.6 \mathrm{~nm}$ and $\mathrm{C}_{1}=0.033$, which are valid for the laser 
wavelength from 400 to $700 \mathrm{~nm}$, is given by [22]:

$L_{a}=\frac{C_{0}+C_{1} \lambda_{L}}{A_{D 1} / A_{G}}$

\subsubsection{Thermogravimetric analysis}

The reactivity of soot samples in $20 \%$ volume fraction $\mathrm{CO}_{2}$ was determined using a thermogravimetric instrument Q5000 (TA Instrument, USA) by loading ca. $8 \mathrm{mg}$ of sample in an $\mathrm{Al}_{2} \mathrm{O}_{3}$ crucible and heating from 30 to $1200^{\circ} \mathrm{C}$ in $\mathrm{CO}_{2}$ at a constant heating rate of $10^{\circ} \mathrm{C}$ $\min ^{-1}$. The kinetic parameters of soot samples were derived by the integral method presented by Coats and Redfern [23]. The reactivities of biomass soot samples were compared using reaction rates calculated from the derived kinetic parameters $\left(\mathrm{A}\right.$ and $\mathrm{E}_{a}$ ) at a fixed gasification temperature of $1000^{\circ} \mathrm{C}$.

\subsection{6. ${ }^{13} \mathrm{C}$ solid state NMR spectroscopy}

Solid-state NMR analysis was carried out on a Nuclear Magnetic Resonance spectrometer, Avance 400 (Bruker, Germany) (9.4 T) operating at Larmor frequencies of 400.13 and $100.58 \mathrm{MHz}$ for ${ }^{1} \mathrm{H}$ and ${ }^{13} \mathrm{C}$, respectively. All experiments were conducted using a double resonance probe equipped with $4 \mathrm{~mm}$ (o.d.) rotors. Samples were analyzed without any additional preparation at room temperature by single-pulse (SP) magic angle spinning (MAS) as well as cross polarization (CP) MAS [24] utilizing high-power ${ }^{1} \mathrm{H}$ two-pulse phase-modulated decoupling (TPPM) [25] during acquisition and employing a spinning rate of $9 \mathrm{kHz}$. The ${ }^{13} \mathrm{C}$ CP/MAS spectra were recorded using a recycle delay of $8 \mathrm{~s}$, a contact time of $1 \mathrm{~ms}$, an acquisition time of $45.9 \mathrm{~ms}$ and 4096 scans, whereas the ${ }^{13} \mathrm{C} \mathrm{SP} / \mathrm{MAS}$ spectra were recorded using a recycle delay of $128 \mathrm{~s}$, an acquisition time of $45.9 \mathrm{~ms}$ and 1080 scans. All ${ }^{13} \mathrm{C}$ NMR spectra were referenced to the carbonyl resonance in an external sample of $\alpha$-glycine at $176.5 \mathrm{ppm}$ [26].

\subsubsection{X-ray photoelectron spectroscopy}

The XPS spectra were collected with an electron spectrometer AXIS Ultra DLD (Kratos Analytical Ltd, UK) using monochromated $\mathrm{Al} \mathrm{K}_{\alpha}$ source operated at $120 \mathrm{~W}$. Analyser pass energy of $160 \mathrm{eV}$ for acquiring survey spectra and a pass energy of $20 \mathrm{eV}$ for individual photoelectron lines were used. The surface potential of dielectric potassium benzoate was stabilized by the spectrometer charge neutralization system. The $\mathrm{C}$ 1 s component for benzene ring ( $\mathrm{sp}^{2}$ carbon) of potassium benzoate sample was set to aromatic $\mathrm{C}-\mathrm{H}$ at $284.7 \mathrm{eV}$ [27]. The binding energy scale of the spectrometer was calibrated using $\mathrm{Au} 4 \mathrm{f}_{7 / 2}$ line of metallic gold at $84.0 \mathrm{eV}$. Processing of the spectra was accomplished with the Vision 2 software (Kratos Analytical Ltd, UK).

\section{Results}

\subsection{Solubility of potassium in char and soot from herbaceous biomass}

Preliminary investigations showed that the ash content of pinewood and beechwood soot samples remained unchanged after the washing in deionized water [20]. However, the removal of water-soluble potassium from herbaceous biomass soot led to a lower reactivity in $\mathrm{CO}_{2}$ gasification. Fig. S-7 illustrates that the washing of soot and char from alfalfa straw and wheat straw does not remove all potassium found in any of the soot samples formed under fast pyrolysis conditions. The relatively small fraction of potassium remaining in the washed soot from alfalfa and wheat straw suggests the formation of the potassiumcarbon complexes or remaining non-soluble potassium fraction.

\subsection{Reactivity of biomass soot}

Fig. 1 shows differential weight loss curves (DTG) for the $20 \%$ volume fraction $\mathrm{CO}_{2}$ gasification of soot samples. The DTG curves show a single broad peak in $\mathrm{CO}_{2}$ gasification, indicating a heterogeneous soot

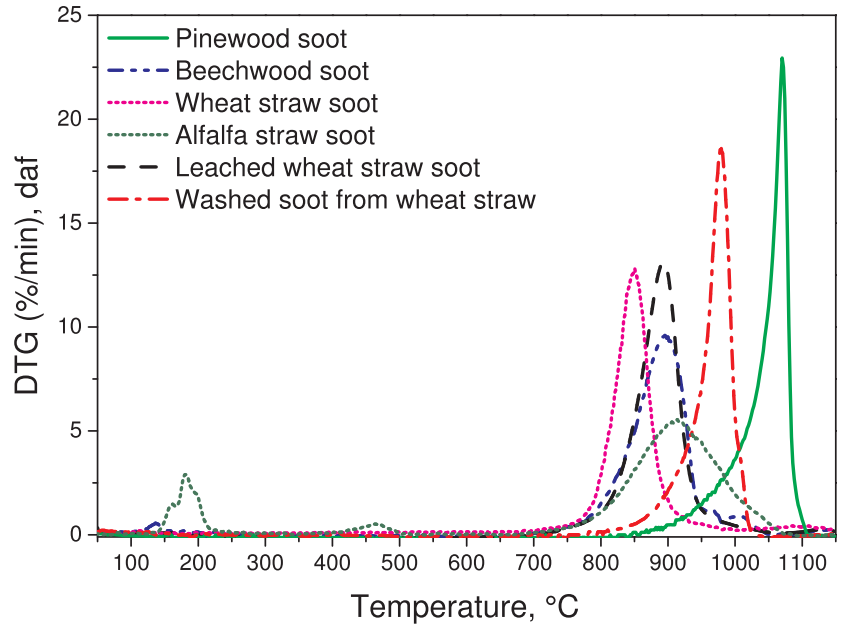

Fig. 1. DTG curves of pinewood, beechwood, wheat straw, leached wheat straw, alfalfa straw soot and washed soot from wheat straw reacted in $(20 \%$ volume fraction $\mathrm{CO}_{2}+80 \%$ volume fraction $\mathrm{N}_{2}$ ). The leached wheat straw soot is soot from wheat straw that was leached in deionized water prior to pyrolysis. The washed soot from wheat straw was prepared by washing soot from original wheat straw in deionized water.

mixture with respect to the composition [28]. The $\mathrm{CO}_{2}$ gasification of all soot except pine and washed soot from wheat straw took place at nearly the same temperature range from 830 to $900^{\circ} \mathrm{C}$. The additional DTG peaks in the $\mathrm{CO}_{2}$ gasification of alfalfa straw soot were related to the reactivity of heavy hydrocarbon compounds [29]. The maximum reaction rate of pinewood soot was about $200^{\circ} \mathrm{C}$ higher than for the other biomasses, and thus, the pinewood soot was clearly less reactive. The washing of wheat straw soot led to a lower reactivity. The maximum reaction rate of washed soot of wheat straw in the $\mathrm{CO}_{2}$ gasification was shifted to temperatures about $100^{\circ} \mathrm{C}$ higher than for the soot from pyrolysis of leached wheat straw and non-treated wheat straw. The calculated $\mathrm{r}_{\max } / \mathrm{r}_{\text {diff }}$ ratio showed that the gasification reaction in the TG analysis was influenced only by chemical kinetic limitations, as shown in the supplemental material (Table S-3).

\section{3. ${ }^{13} \mathrm{C}$ solid state NMR spectroscopy}

By ${ }^{13} \mathrm{C}$ solid-state MAS NMR it was demonstrated that all soot samples were characterized by a predominantly graphene-like structure [30], as shown in the supplemental material (Figure S-9). Only in alfalfa straw soot an additional presence of a carboxylate carbon was detected. The chemical shift of this agrees well with that of the potassium-calcium carbonate butschliite [31-33].

\subsection{X-ray photoelectron spectroscopy}

The XPS spectra of pinewood and beechwood soot mainly exhibit the carbon and oxygen lines with some traces of sodium, whereas herbaceous biomass soot samples additionally showed $\mathrm{K} 2 \mathrm{p}$ and $\mathrm{Cl} 2 \mathrm{p}$ lines, as shown in the supplemental material (Table S-4). The $\mathrm{K}$ and $\mathrm{Cl}$ atomic concentrations for the alfalfa straw soot were 3.5 and 1.2 at.\%, whereas the $\mathrm{K}$ and $\mathrm{Cl}$ atomic ratio in pure $\mathrm{KCl}$ is $1: 1$, respectively. The remaining potassium (2.3 at.\%) might have been bounded to the soot matrix as $\mathrm{KOH}$ and/or $\mathrm{K}_{2} \mathrm{CO}_{3}$ which was not detected (or fitted) in $\mathrm{C} 1 \mathrm{~s}$ spectrum due to small amounts. The present XPS results strongly suggest that potassium species were incorporated in straw soot particles mostly as water-soluble $\mathrm{KCl}, \mathrm{K}_{2} \mathrm{CO}_{3}$ and $\mathrm{KOH}$.

\subsection{Raman spectroscopy}

Raman spectroscopy was carried out to examine primary differences 
in the carbon structure of soot samples. The calculated integrated peak area ratio $\left(A_{D 4} / \mathrm{A}_{G}\right)$ in supplementary Table S-5 showed that the beechwood and leached wheat straw soot samples obtained the highest amount of carboxylates $(0.2$ and 0.3$)$, whereas the $\mathrm{A}_{D 4} / \mathrm{A}_{G}$ ratio of wheat straw soot was the lowest (0.04). The relative $A_{D 4} / A_{G}$ ratio of pinewood soot is lower than for beechwood soot due to the low content of acetyl groups in hemicellulosic fraction of softwood [34]. All soot samples based on the $\mathrm{A}_{D 1} / \mathrm{A}_{G}$ ratios exhibited a common structure of amorphous carbon and nano-crystalline graphite, as discussed by Ferrari and Robertson [35]. In addition, the alfalfa straw soot contained a higher fraction of distorted small PAH clusters within the amorphous carbon than other soot samples, as observed experimentally by Abboud et al. [36]. The average extensions of graphene stacks $\left(\mathrm{L}_{a}\right)$ from the Raman bands in beechwood, wheat straw, alfalfa straw and leached wheat straw soot were lower than those of pinewood and washed soot from wheat straw. The size of one aromatic ring is $2.5 \AA$ [37], and therefore, the size of PAHs $\left(\mathrm{L}_{a}=21-26 \AA\right)$ is equivalent to the size of $8-10$ aromatic rings.

\subsection{X-ray diffraction}

The XRD analysis did not show any significant differences between woody and herbaceous soot samples in terms of graphitization, as shown in the supplemental material (Figure S-41). The XRD analysis of soot indicated formation of turbostratic or random layer lattice structures. The additional reflections, detected by the XRD measurements of wheat straw and alfalfa straw soot, were attributed to $\mathrm{KCl}$ and $\mathrm{KHCO}_{3}$.

\section{Discussion}

The thermogravimetric experiments demonstrated significant differences in $\mathrm{CO}_{2}$ reactivity for soot from pyrolysis of wood and herbaceous biomass. The $\mathrm{CO}_{2}$ gasification of beechwood, wheat straw, alfalfa straw and leached wheat straw soot prepared at $1250^{\circ} \mathrm{C}$ took place at nearly the same temperature range, whereas the maximum reaction rate of pinewood soot and washed soot from wheat straw was shifted to higher temperatures, indicating a lower reactivity. The reactivity of soot samples can be affected by the differences in carbon structure and alkali content $[6,38,39]$. Lapuerta et al. [40] studied soot samples generated from the combustion of biodiesel and diesel fuels using thermogravimetric analysis and Raman spectroscopy and the authors found that the impact of soot nanostructure on the oxidation reactivity is significant. The biodiesel soot has a higher initial degree of graphitization with the higher curvature of the carbon fringes of an average particle size which increases the probability of collapsing into smaller fringes, and thus, enhances the reactivity. Trubetskaya et al. [41] studied the impact of lignocellulosic compounds and monolignols on the biomass soot reactivity and showed that the high content of extractives and lignin in the pinewood and beechwood could lead to the lower reactivity of woody soot. The previous studies also showed that the maximal reaction rates of extractives and lignin soot samples were less reactive than the cellulose and hemicellulose soot, emphasizing a dominating role of differences in lignocellulosic composition on the soot reactivity. Interestingly, the authors found that the $\mathrm{CO}_{2}$ reactivities of softwood and wheat straw lignin soot were similar beside the fact that the low ash-containing softwood lignin soot was expected to be less reactive than the $\mathrm{Na}^{+}$rich wheat straw lignin soot.

In the present study, the Raman spectroscopy analysis showed that the alfalfa straw soot consists of small PAH clusters within the amorphous carbon with high curvatures of carbon fringes forming higher specific surface area, leading to the higher reactivity. In addition, the alfalfa and wheat straw soot samples obtained the highest $\mathrm{A}_{D 1} / \mathrm{A}_{G}$ ratio. Thus, more defective graphene sheets could form smaller carbon segments with a higher specific surface area resulting in the high $\mathrm{CO}_{2}$ reactivity. This indicates that the carbon structure has an influence on the observed differences in soot reactivity. In addition, the previous Raman spectroscopy analysis indicated that the differences in carbon structure of soot from holocelluloses, lignin and monolignols were small [41]. However, the ash-forming elements are known to influence both the shape and nanostructure of pinewood soot particles during the entrained flow gasification of biomass [6].

In the present work, the Raman spectroscopy results suggested that the released alkali metal ions in the biomass pyrolysis had an influence on the soot carbon structure, leading to the formation of defects in the carbon matrix. Previous results showed that the soot $\mathrm{CO}_{2}$ reactivity depends mainly on the alkali content in the original fuel and less on the soot nanostructure and soot particle size [42]. For the Ca and Na rich biodiesel soot, higher oxidation reactivities were observed than for the low ash-containing farnesane and diesel soot samples [43]. The authors also indicated that $\mathrm{Ca}, \mathrm{Na}$, and $\mathrm{P}$ compounds had a dominant role on the soot reactivity compared to the differences in nanostructure of biodiesel and diesel soot samples. Gustafsson et al. [44] observed that Ca was a dominant ash-forming element in wood pellet combustion. In the present study, the ash content in the original beechwood (1.4\%) was higher than in the pinewood $(0.3 \%)$, leading to the higher $\mathrm{K}$ release to the gas phase and so more $\mathrm{K}$ incorporation in the beechwood soot particles compared to the pinewood pyrolysis. The ash content in the original alfalfa straw (7.2\%) was also higher than in the non-treated wheat straw $(4.1 \%)$ and leached wheat straw (2.1\%). The inorganic elements in all herbaceous biomass soot samples were mainly $\mathrm{K}, \mathrm{Cl}, \mathrm{S}$, and Si. Previous equilibrium calculations and X-ray diffraction reflections suggested an incorporation of water-soluble $\mathrm{KCl}$ in the alfalfa, non-treated and leached wheat straw soot samples [45]. The present results showed that $50 \%$ more of potassium was condensed onto the leached wheat straw soot compared to the non-treated wheat straw soot where potassium was probably retained as a silicate in the char. The lower $\mathrm{Cl}$ content in the leached wheat straw might indicate that potassium was released in the form of $\mathrm{KOH}$, possibly forming $\mathrm{K}_{2} \mathrm{CO}_{3}$ [46]. Based on the XRD and XPS analysis results it was concluded that the potassium species were incorporated in the alfalfa and wheat straw soot particles mostly as $\mathrm{KOH}, \mathrm{KCl}, \mathrm{KHCO}_{3}$ and $\mathrm{K}_{2} \mathrm{CO}_{3}$. The present results showed that potassium compounds represent major alkali metal ions incorporated into the biomass soot matrix. In addition, the XPS results showed that the elemental potassium was not bonded to the soot matrix in phenolate groups and was mainly adsorbed as potassium hydroxide and/or potassium carbonate on the herbaceous soot particle surfaces which is probably due to the short contact time in high-temperature biomass pyrolysis. The XPS results also indicated that the alkali metal compounds were not detected for pinewood soot. The water-soluble salts affect the biomass soot reactivity [42]. Soot from alfalfa straw, wheat straw, beechwood and leached wheat straw was 14 times more reactive than pinewood soot and washed soot from wheat straw, due to the stronger catalytic effect of ash compounds. Significantly smaller differences in $\mathrm{CO}_{2}$ reactivity were observed for the pinewood soot and washed soot from wheat straw (2 times), as shown in the supplemental material (Table S-2). The amount and composition of the ash forming matter in the lignocellulosic materials lead to the differences in soot reactivity. The potassium content of leached wheat straw soot was lower than for alfalfa straw and wheat straw soot, and higher than for beechwood soot. However, the differences in reactivity of soot from beechwood, wheat straw, alfalfa straw and leached wheat straw were small, as shown in Fig. 2. The remaining potassium compounds in the washed soot from wheat straw led to a slightly higher reactivity compared to the pinewood soot. Thus, the present study indicated that the water-soluble salts determine the catalytic gasification rate because electron donor-acceptor (EDA) complexes and C-O-K groups on the soot surface were not formed. The high reactivity of potassium rich herbaceous soot samples was related to the reduction-oxidation cycles of $\mathrm{K}_{2} \mathrm{CO}_{3}$, elemental potassium, and $\mathrm{K}_{2} \mathrm{O}$ according to Eqs. (2)-(4) $[47,48]$ :

$\mathrm{K}_{2} \mathrm{CO}_{3}+2 \mathrm{C} \rightarrow 2 \mathrm{~K}+3 \mathrm{CO}$ 


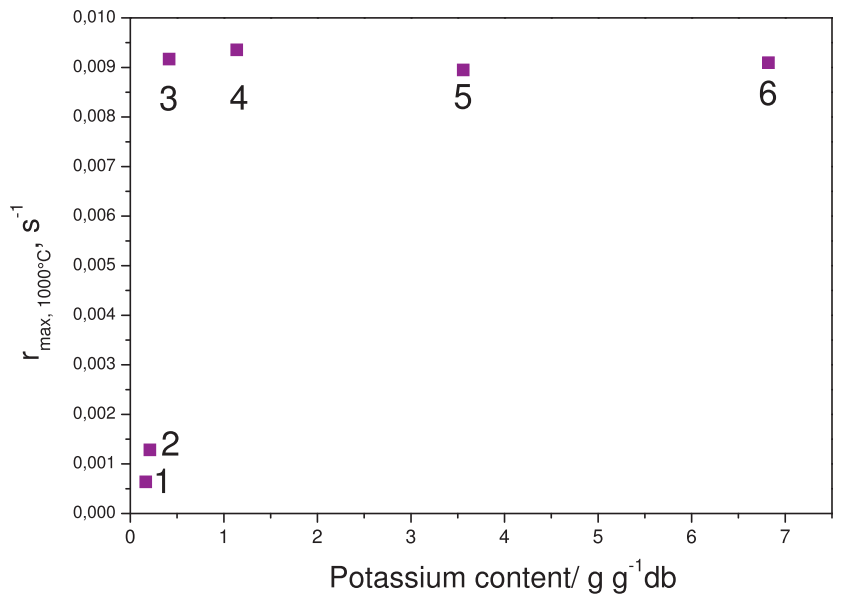

Fig. 2. Maximal reaction rate at $1000^{\circ} \mathrm{C}$ (results from Table S-2) versus potassium content in soot from pinewood, beechwood wheat straw, alfalfa straw, leached wheat straw and washed soot from wheat straw (results from Figs. S$5-S-7)$. The potassium content is shown in wt $\%$ relative to the soot $\left(\mathrm{g} \mathrm{g}^{-1}\right.$ on dry basis).

$2 \mathrm{~K}+\mathrm{CO}_{2} \rightarrow \mathrm{K}_{2} \mathrm{O}+\mathrm{CO}$

$\mathrm{K}_{2} \mathrm{O}+\mathrm{CO}_{2} \rightarrow \mathrm{K}_{2} \mathrm{CO}_{3}$

In addition, the catalytic effect of potassium on the reactivity remained similar after a certain concentration of potassium is reached in the soot particles, and thus, the changes in reactivity of soot from pyrolysis of alfalfa straw, wheat straw and leached wheat straw were small. The removal of potassium from the original wheat straw does not affect the soot reactivity. In contrast, the estimated activation energy of wheat straw soot increased from 209 to $225 \mathrm{~kJ} \mathrm{~mol}^{-1}$ after the washing in deionized water, as shown in the supplemental material (Table S-2), indicating that the removal of potassium leads to a lower soot reactivity. Fig. 2 shows that the reactivity of soot samples generated from dry feedstocks with potassium concentration $>0.3 \mathrm{wt} \%$ changed only slightly. The contact between alkali metals and carbon is an essential parameter in the catalytic gasification of biomass that can be improved by mobility of the alkali metals [49]. The present results showed that the $\mathrm{K}_{2} \mathrm{CO}_{3}$ had a good contact with the soot carbonaceous matrix, leading to the higher $\mathrm{CO}_{2}$ reactivity with the increased content of potassium until saturation was reached.

\section{Conclusion}

The novelty of this work relies on the fact that potassium is unlikely to be bonded to oxygen-containing surface groups in the soot matrix during high temperature pyrolysis. The present results showed that potassium was deposited on the soot surface as water-soluble alkali such as $\mathrm{KCl}, \mathrm{KOH}, \mathrm{KHCO}_{3}$ and $\mathrm{K}_{2} \mathrm{CO}_{3}$. The thermogravimetric analysis showed that the differences in $\mathrm{CO}_{2}$ reactivity are large for soot from wood and herbaceous biomass pyrolysis. The $\mathrm{CO}_{2}$ reactivity of soot depends mainly on the potassium content in the original fuel and less on the carbon chemistry. However, the catalytic effect of potassium on the reactivity remains the same after a certain potassium amount was deposited on the surface of soot particles during pyrolysis. The low ash containing pinewood soot was less reactive with the more ordered graphene structure than other soot samples. The carbon structure of alfalfa and wheat straw soot appeared more graphene disordered and contributed to the greater reactivity in $\mathrm{CO}_{2}$ gasification. The present work emphasized a significant influence of both potassium and carbon structure on the biomass soot reactivity.

\section{Acknowledgements}

The authors gratefully acknowledge financial support from the Kempe Foundation, the Swedish Energy Agency and the Swedish strategic research program Bio4Energy. The authors acknowledge the facilities and technical support of Dr. Nikki Lee of the Umeå Core Facility for Electron Microscopy (UCEM) at the Chemical and Biological Centre (KBC), Dr. Andras Gorzsas, Dr. Nils Skoglund and Dr. Markus Broström at Umeå University. We acknowledge Avery Brown from Worcester Polytechnic Institute for the article proof-reading.

\section{Appendix A. Supplementary data}

Supplementary data associated with this article can be found, in the online version, athttp://dx.doi.org/10.1016/j.fuel.2018.03.140.

\section{References}

[1] Carlsson P, Ma C, Molinder R, Weiland F, Wiinikka H, Öhman M, et al. Slag formation during oxygen-blown entrained-flow gasification of stem wood. Energy Fuels 2014;28:6941-52.

[2] Ma C, Backman R, Öhman M. Thermochemical equilibrium study of slag formation during pressurized entrained-flow gasification of woody biomass. Energy Fuels 2015;29:4399-406.

[3] Chen SG, Yang RT. The Active Surface Species in Alkali-Catalyzed Carbon Gasification: Phenolate [C-O-M) Groups vs Clusters (Particles]. J Catal 1993;141:102-13.

[4] Septien S, Valin S, Peyrot M, Dupont C, Salvador S. Characterization of char and soot from millimetric wood particles pyrolysis in a drop tube reactor between $800^{\circ} \mathrm{C}$ and $1400^{\circ} \mathrm{C}$. Fuel $2014 ; 121: 216-24$.

[5] Akuzawa N, Yoshioka J, Ozaki C, Tokuda M, Ohkura K, Soneda Y. Preparation and characterization of sodium-graphite intercalation compounds. Mol Cryst Liq Cryst 2002;388(1):1-7.

[6] Wiinikka H, Weiland F, Pettersson E, Öhrman O, Carlsson P, Stjernberg J. Characterization of submicron particles produced during oxygen blown entrained flow gasification of biomass. Combust Flame 2014;161:1923-34.

[7] Kopyscinski J, Rahman M, Gupta R, Mims CA, Hill JM. $\mathrm{K}_{2} \mathrm{CO}_{3}$ catalyzed $\mathrm{CO}_{2}$ gasification of ash-free coal. Interactions of the catalyst with carbon in $\mathrm{N}_{2}$ and $\mathrm{CO}_{2}$ atmosphere. Fuel 2014;117:1181-9.

[8] Wen YW. Mechanisms of alkali metal catalysis in the gasification of coal, char, or graphite. Cat Rev Sci Eng 1980;22(1):1-28.

[9] Sekhar MVC, Ternan M. Catalytic gasification of char from hydrocracked pitch. Fuel Process Tech 1982;6:61-73.

[10] Wigmans T, Elfring R, Moulijn JA. On the mechanism of the potassium carbonate catalysed gasification of activated carbon: the influence of the catalyst concentration on the reactivity and selectivity at low steam pressures. Carbon 1983;21(1):1-12.

[11] Dresselhaus MS, Dresselhaus G, Eklund PC. Science of fullerenes and carbon nanotubes. Academ Press; 1996.

[12] Winter J, Kuzmany H. Physical properties and phase transitions in AC(60). Carbon 1998;36(5-6):599-601.

[13] Tycko R. Molecular orientational dynamics in solid C-70 investigation by one-dimensional and 2-dimensional magic-angle-spinning nuclear-magnetic-resonance. Phys Chem Solids 1993;54(12):1713-23.

[14] Gunnarsson O. Superconductivity in fullerides. Carbon 1997;69(2):575-606.

[15] Skokan EV, Tarasov VP, Privalov VI, Aleshina VE, Muravlev YB, Arkhangelskii IV. Intercalation of potassium into fullerite $\mathrm{C}_{60}:{ }^{13} \mathrm{C}$ and ${ }^{39} \mathrm{~K}$ NMR data. Electrochem Soc Proc 2003;15:509-14.

[16] Chun KY. Controlling the doping level of double-walled carbon nanotubes by using aromatic hydrocarbon complexes. RSC Adv 2014;4:8879-82.

[17] Caballero A. Adsorption and oxidation of K deposited on graphite. Surf Sci 1996;364:253-65.

[18] Li Q, Wang X, Xin Y, Zhang Z, Zhang Y, Hao C, et al. A unified intermediate and mechanism for soot combustion on potassium-supported oxides. Sci Rep 2014;4:4725-31.

[19] Mejer R, Weeda M, Kapteijn F, Moulijn JA. Catalyst loss and retention during alkalicataluzed carbon gasification in $\mathrm{CO}_{2}$. Carbon 1991;29(7):929-41.

[20] Trubetskaya A, Jensen PA, Jensen AD, Garcia Llamas AD, Umeki K, Glarborg P. Effect of fast pyrolysis conditions on biomass solid residues at high temperatures. Fuel Process Tech 2016;143:118-29.

[21] Sadezky A, Muckenhuber H, Grothe H, Niessner R, Pöschl U. Raman spectroscopy of soot and related carbonaceous materials: spectral analysis and structural information. Carbon 2005;43:1731-42.

[22] Matthews MJ, Pimenta MA, Dresselhaus G. Origin of dispersive effects of the Raman D band in carbon materials. Phys Rev B 1999:59(10):R6585-8.

[23] Coats AW, Redfern JP. Kinetic parameters from thermogravimetric data. Nature 1964;201:68-9.

[24] Peersen OB, Wu X, Kustanovich I, Smith SO. Variable-amplitude cross-polarization MAS NMR. J Magn Reson Ser A 1993;3:334-9.

[25] Bennett AE, Rienstra CM, Auger M, Lakshmi KV, Griffin RG. Heteronuclear 
decoupling in rotating solids. J Chem Phy 1995;103:6951-8.

[26] Potrzebowski MJ, Tekely P, Dusausoy Y. Comment to ${ }^{13} \mathrm{C}$ NMR studies of alpha and gamma polymorphs of glycine. Solid State Nucl Magn Reson 1998;11(3-4):253-7.

[27] Beamson G, Briggs D. The XPS of Polymers Database. CD Version 1.0. SurfaceSpectra Ltd; 2000.

[28] Russell NV, Beeley TJ, Man CK, Gibbins JR, Williamson J. Development of TG measurements of intrinsic char combustion reactivity for industrial and research purposes. Fuel Process Tech 1998;57(2):113-30.

[29] Zhang D, Ma Y, Zhu M. Nanostructure and oxidative properties of soot from a compression ignition engine: the effect of a homogeneous combustion catalyst. Proc Combust Inst 2013;34:1869-76.

[30] Freitas JCC, Emmerich FG, Bonagamba TJ. High-resolution solid-state NMR study of the occurrence and thermal transformations of silicon-containing species in biomass materials. Chem Mater 2000;12(3):711-8.

[31] Papenguth HW, Kirkpatrick RJ, Montez B, Sandberg PA. ${ }^{13} \mathrm{C}$ MAS NMR spectroscopy of inorganic and biogenic carbonates. Am Miner 1989;74:1152-8.

[32] Stueber D, Patterson D, Maybe CL, Orendt AM, Grant DM, Parry RW. Carbonates, thiocarbonates, and the corresponding monoalkyl derivatives. 1. Their preparation and isotropic ${ }^{13} \mathrm{C}$ NMR chemical shifts. Inorg Chem 2001;40:1902-11.

[33] Shatskiy A, Borzdov YM, Litasov KD, Sharygin IS, Palyanov YN, Ohtani E. Phase relationship in the system $\mathrm{K}_{2} \mathrm{CO}_{3}-\mathrm{CaCO}_{3}$. Fuel 2014;117:1181-9.

[34] Sun Y, Cheng J. Hydrolysis of lignocellulosic materials for ethanol production: a review. Biores Tech 2002;83:1-11.

[35] Ferrari AC, Robertson J. Raman spectroscopy of amorphous, nanostructured, diamond-like carbon, and nanodiamond. Phil Trans R Soc Lond 2004;362:2477-512.

[36] Abboud J, Schobing J, Legros G, Bonnety J, Tschamber V, Brillard A, et al. Impacts of oxygenated compounds cocentration on sooting propensities and soot oxidative reactivity: application to diesel and biodiesel surrogates. Fuel 2017;193:241-53.

[37] Hayashida K, Nagaoka S, Ishitani H. Growth and oxidation of graphitic crystallites in soot particles within a laminar diffusion flame. Fuel 2014;128:148-54.

[38] Müller JO. Investigations on environmental carbons [Ph.D. thesis]. Technical University of Berlin; 2012.
[39] Liati A, Eggenschwiler PD, Schreiber D, Zelenay V, Ammann M. Variations in diesel soot reactivity along the exhaust after-treatment system, based on the morphology and nanostructure of primary soot particles. Combust Flame 2013;160(3):671-81.

[40] Lapuerta M, Oliva F, Agudelo JR, Boehman AL. Effect of fuel on the soot nanostructure and consequences on loading and regeneration of diesel particulate filters. Combust Flame 2012;159:844-53.

[41] Trubetskaya A, Brown A, Tompsett GA, Timko MT, Umeki K, Kling J, et al. Characterization and reactivity of soot from fast pyrolysis of lignocellulosic compounds and monolignols. Appl Energy 2018;212:1489-500.

[42] Trubetskaya A, Jensen PA, Jensen AD, Garcia Llamas AD, Umeki K, Kling J, et al. Effects of several types of biomass fuels on the yield, nanostructure and reactivity of soot from fast pyrolysis at high temperatures. Appl Energy 2016;171:468-82.

[43] Soriano JA, Agudelo JR, Lopez AF, Armas O. Oxidation reactivity and nanostructural characterization of the soot coming from farnesane - a novel diesel fuel derived from sugar cane. Carbon 2017;125:516-29.

[44] Gustafsson E, Strand M, Sanati M. Physical and chemical characterization of aerosol particles formed during the thermochemical conversion of wood pellets using a bubbling fluidized bed gasifier. Energy Fuels 2007;21:3660-7.

[45] Trubetskaya A, Jensen PA, Jensen AD, Steibel M, Spliethoff H, Glarborg P, Hofmann Larsen F. Comparison of the high temperature chars of wheat straw and rice husk with respect to chemistry, morphology and reactivity. Biomass Bioenergy 2016;86:76-87.

[46] Dayton DC, Milne TA. Laboratory measurements of alkali metal containing vapors released during biomass combustion. In: Baxter L, DeSollar R, editors. Applications of advanced technology to ash-related problems in boilers. Plenum Press; 1996.

[47] Miro EE, Ravelli F, Ulla MA, Cornaglia LM, Querini CA. Catalytic combustion of diesel soot on Co, K supported catalysts. Catal Today 1999;53(4):631-8.

[48] Neeft PA, Makkee M, Moulijn JA. Catalytic oxidation of carbon black - I. Activity of catalysts and classification of oxidation profiles. Fuel 1998;77(3):111-9.

[49] Neeft PA, Makkee M, Moulijn JA. Catalysts for the oxidation of soot from diese exhaust gases. I. An exploratory study. Appl Catal B: Environ 1996;8(1):57-78. 